\title{
SCAPHOID MALUNION
}

\author{
RYOGO NAKAMURA, TOSHIHIKO IMAEDA, TAKAYUKI MIURA
}

From Nagoya University School of Medicine, Japan

\begin{abstract}
We reviewed 10 patients with symptomatic malunion of a carpal scaphoid fracture. All had displacement with dorsiflexed intercalated segment instability, and suffered from pain, restricted range of movement at the wrist and decreased grip strength. The restriction of flexion-extension and the decreased grip strength correlated with the severity of the DISI deformity.

Seven patients had a corrective osteotomy, using an anterior wedge-shaped bone graft with internal fixation by Herbert screw, and all had satisfactory results. We believe that symptoms associated with scaphoid malunion are related to consequent carpal deformity.
\end{abstract}

Chronic symptoms after a scaphoid fracture are frequently associated with a humpback deformity of the scaphoid (Fisk 1970) and dorsiflexed intercalated segment instability (DISI) of the wrist (Linscheid et al 1972), and nonunion is frequent where there is displacement or deformity (Eddeland et al 1975; Cooney, Dobyns and Linscheid 1980; Weber 1980). In some cases, union takes place with persistent deformity of the scaphoid.

We can find no detailed clinical report of cases of malunion, although Burgess (1987) has shown experimentally that this may produce symptoms and that a humpback deformity will limit extension of the wrist. Symptomatic malunion can be treated by corrective osteotomy with reduction of the deformity, but this is difficult because of the small size of the scaphoid and the risk of nonunion of the osteotomised bone. To overcome these difficulties, we have developed a simple method of reducing DISI deformity using Kirschner wires (Nakamura et al 1987), a wedge-shaped anterior bone graft (Fisk 1970, 1979) and internal fixation with a Herbert screw (Herbert and Fisher 1984). We now report on the symptoms of scaphoid malunion and the effect of corrective osteotomy.

\section{PATIENTS AND METHODS}

Ten patients with scaphoid malunion and wrist pain were admitted to Nagoya University Hospital between 1982 and 1988. Of these, eight had been treated elsewhere

R. Nakamura, MD, Associate Professor, Director of Hand Surgery

T. Imaeda, MD, Staff Surgeon

T. Miura, MD, Professor of Orthopaedic Surgery

Department of Orthopaedic Surgery, Branch Hospital of Nagoya,

University School of Medicine, 1-1-20 Daikominami, Higashiku,

Nagoya 461, Japan.

Correspondence should be sent to $\mathrm{Dr} \mathrm{R}$. Nakamura

(C) 1991 British Editorial Society of Bone and Joint Surgery

$0301-620 X / 91 / 1037 \$ 2.00$

J Bone Joint Surg [ Br] 1991 ; 73-B:134-7. by plaster cast immobilisation. The other two patients (cases 8 and 9) had had no treatment. In all cases radiographs showed an offset of the fracture site, with DISI deformity. Union of the scaphoid fracture was radiographically obvious in seven cases (Fig. 1); in the other three covert malunion was confirmed at operation (cases 4, 5 and 10; Fig. 2).

The patients' ages ranged from 13 to 57 years, half being in their teens. The fracture site was at the waist of the scaphoid in eight and the distal third in two. No case of malunion in the proximal third was seen. Seven of the 10 patients had corrective osteotomy, and one (case 10) had a radial styloidectomy. The other two patients (cases 8 and 9) refused surgery (Table I).

Methods. Wrist pain, range of wrist flexion-extension and grip strength were recorded. Standard posteroanterior, lateral and oblique views, with a dynamic series of radiographs were obtained for each patient. The radiolunate angle, scapholunate angle (Sarrafian, Melamed and Goshgarian 1977) and carpal height ratio (Youm et al 1978) were measured on a lateral radiograph. The scaphoid length (Fernandez 1984) was measured on a maximally ulnar-deviated postero-anterior view.

Operative procedure. Using the anterior approach described by Herbert and Fisher (1984), the distal and anterior surfaces of the scaphoid are exposed. Division of the radioscaphoid-capitate ligament is avoided when possible; if it interferes with the operation, it is divided only partially so that its continuity is preserved.

Osteotomy through the fracture line is performed with small chisels, and a $1.5 \mathrm{~mm}$ Kirschner wire is inserted from the dorsum of the wrist into the lunate. Reduction is then performed under image intensification, the lunate being levered into a palmar-flexed position by the Kirschner wire, until the DISI and humpback deformities are corrected (Fig. 2c). The Kirschner wire is bent and fixed distally by sterilised adhesive tape or bandage to the dorsum of the hand so that reduction of the DISI deformity is maintained. 


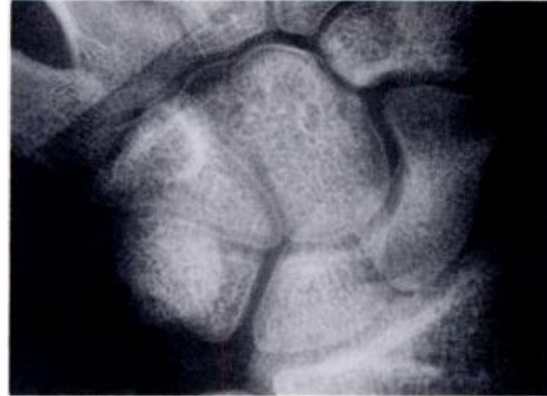

Fig. 1a

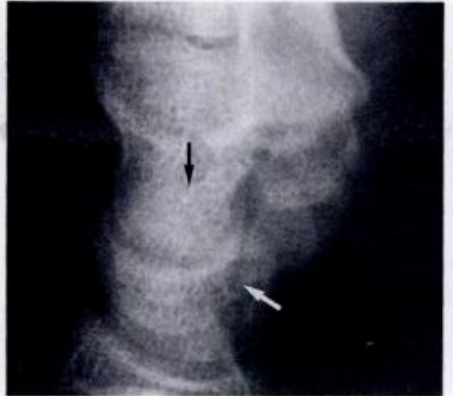

Fig. 1b

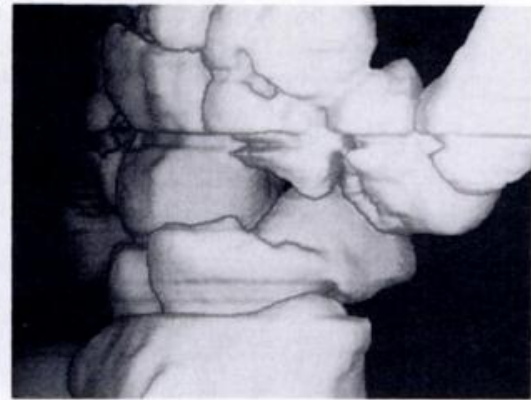

Fig. 1c

Definite malunion (case 9). A left scaphoid fracture was sustained in a motorcycle accident and treated by plaster cast immobilisation for two months. At six months there was persistent wrist pain. Figure la - PA radiograph in maximum ulnar deviation showing union of the scaphoid fracture. Figure $1 \mathrm{~b}$ - Lateral radiograph showing mild DISI deformity with a dorsiflexed lunate. The displacement of the fracture can be seen (arrows). Figure 1c - Oblique surface view of a 3-D CT reconstruction showing the deformity of the scaphoid.

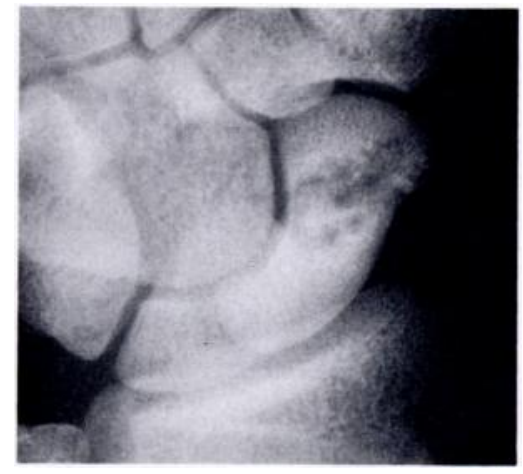

Fig. 2a

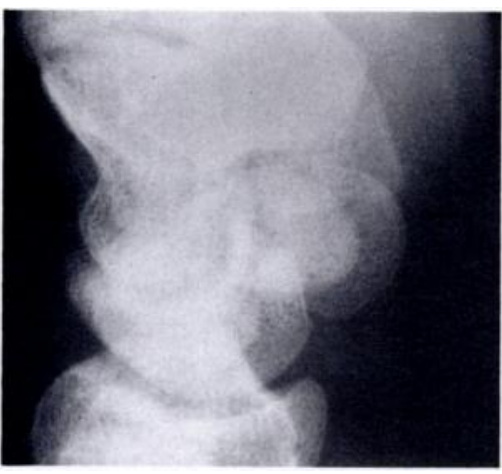

Fig. 2b

Covert malunion (case 5). A left scaphoid fracture was sustained playing football and treated by plaster immobilisation for two months. At one year pain persisted. Figure $2 a$ - pre-operative PA radiograph in maximum ulnar deviation showing delayed union. Figure $2 b$ - Lateral radiograph showing dorsiflexed lunate, severe DISI deformity and humpback deformity of the scaphoid.

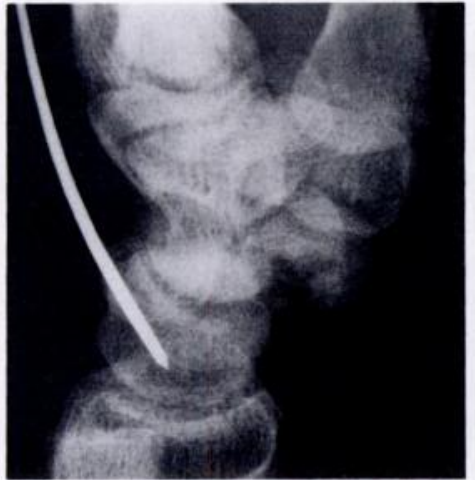

Fig. 2c

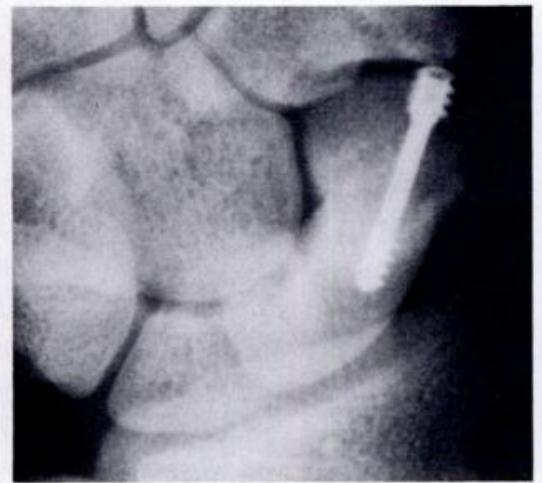

Fig. 2d

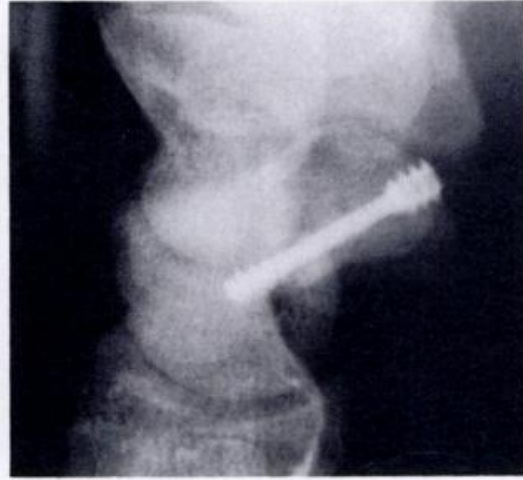

Fig. 2e

Figure $2 c$ - Intra-operative lateral radiograph showing the Kirschner wire reduction, holding the lunate in a palmar-flexed position with the DISI deformity reduced, and the humpback deformity corrected. Figure $2 \mathrm{~d}$ - Postoperative PA view in maximum ulnar deviation showing union at the osteotomy site. Figure $2 e$ - Postoperative lateral view showing good reduction of the scaphoid and correct carpal alignment. 
Table I. Details of 10 patients with malunion of the carpal scaphoid

\begin{tabular}{|c|c|c|c|c|c|c|c|c|c|c|}
\hline \multirow[b]{2}{*}{ Case } & \multirow[b]{2}{*}{ Age } & \multirow[b]{2}{*}{ Sex } & \multirow[b]{2}{*}{$\begin{array}{l}\text { Duration after } \\
\text { injury (mth) }\end{array}$} & \multirow[b]{2}{*}{ Treatment } & \multicolumn{6}{|c|}{ Measurements: pre-operative/postoperative (uninjured side) } \\
\hline & & & & & $\begin{array}{l}\text { Follow-up } \\
\text { (mth) }\end{array}$ & $\begin{array}{l}\text { Range of flexion - } \\
\text { extension (degrees) }\end{array}$ & $\begin{array}{l}\text { Grip strength } \\
\text { (kg) }\end{array}$ & $\begin{array}{l}\text { Radiolunate } \\
\text { angle* (degrees) }\end{array}$ & $\begin{array}{l}\text { Scapholunate } \\
\text { angle (degrees) }\end{array}$ & $\begin{array}{l}\text { Scaphoid } \\
\text { length }(\mathrm{mm})\end{array}$ \\
\hline 1 & 26 & $\mathbf{M}$ & 4 & Osteotomy & 30 & $94 / 140(167)$ & $16 / 43(47)$ & $-25 / 0$ & $66 / 57(55)$ & $26 / 27(27)$ \\
\hline 2 & 13 & $\mathbf{M}$ & $9 \dagger$ & Osteotomy & 36 & $121 / 43 \quad(144)$ & $19 / 36(42)$ & $-17 /-8(-7)$ & $85 / 63(67)$ & $19 / 19(19)$ \\
\hline 3 & 19 & $\mathbf{M}$ & $16 \dagger$ & Osteotomy & 42 & $110 / 128(166)$ & $25 / 31(35)$ & $-18 / 6 \quad(1)$ & $84 / 60(63)$ & $21 / 23(23)$ \\
\hline 4 & 22 & $\mathbf{M}$ & 8 & Osteotomy & 25 & $42 / 129(170)$ & $21 / 57(68)$ & $-28 / 0(-3)$ & $70 / 55(56)$ & $25 / 29$ \\
\hline 5 & 16 & $\mathbf{M}$ & 12 & Ostoetomy & 24 & $76 / 134(140)$ & $20 / 51 \quad(57)$ & $-25 / 3$ & $74 / 46(58)$ & $26 / 27(27)$ \\
\hline 6 & 19 & $\mathbf{M}$ & 21 & Osteotomy & 26 & $97 / 149(165)$ & $47 / 53(58)$ & $-9 / 7$ & $70 / 67(50)$ & $26 / 27(27)$ \\
\hline 7 & 31 & $\mathbf{M}$ & 3 & Osteotomy & 25 & $120 / 33 \quad(175)$ & $38 / 44(46)$ & $22 / 30$ & $38 / 38 \quad(35)$ & $30 / 32$ \\
\hline 8 & 18 & $\mathbf{M}$ & 3 & Nil & 12 & $171 /-\quad(174)$ & $30 /-(35)$ & $-2 /-\quad(10)$ & $57 /-(48)$ & $25 /-(25)$ \\
\hline 9 & 17 & $\mathbf{M}$ & 6 & Nil & 12 & $70 /-\quad(144)$ & $15 /-(42)$ & $-14 /-\quad$ (7) & $89 /-(50)$ & $24 /-(26)$ \\
\hline 10 & 57 & $\mathbf{F}$ & 6 & $\begin{array}{l}\text { Radial } \\
\text { styloidectomy }\end{array}$ & 84 & $82 / 124(152)$ & $15 / 16(22)$ & $-11 /-11(13)$ & $47 / 47(41)$ & $26 / 26(28)$ \\
\hline
\end{tabular}

*radiolunate angle recorded as plus when the lunate was palmar flexed ffracture in distal third; all others at waist of scaphoid

The bone defect in the scaphoid resulting from the reduction is then grafted, using a wedge-shaped piece of bone from the iliac crest. The graft is then fixed into the osteotomy site, using internal fixation by a Herbert screw. The Kirschner wire is then removed, the wound sutured in layers, and the wrist immobilised by plaster or casting tape for four to eight weeks.

\section{RESULTS}

Pre-operative symptoms and radiographs. All patients had wrist pain before operation. Pre-operative flexion-extension of the wrist was from $24 \%$ to $85 \%$ of that on the normal side, with grip strength decreased to $37 \%$ to $86 \%$ of normal. The radiolunate angle was decreased by from $10^{\circ}$ to $36^{\circ}$ and the scapholunate angle was increased by from $3^{\circ}$ to $39^{\circ}$. The carpal height ratio was reduced by 0.01 to 0.03 in eight cases and was equal to the uninjured side in the other two. The scaphoid length was shorter by 1 to $4 \mathrm{~mm}$ in eight cases, and equal in the other two.

Radiolunate angle and pre-operative symptoms. The severity of the DISI deformity was assessed from the radiolunate angle, and related to the range of flexionextension of the wrist and to grip strength. There was a significant correlation with both types of functional impairment (Fig. 3). We found no significant correlation between the scapholunate angle and flexion-extension or grip strength.

Operative results. All seven patients who had corrective osteotomies had an uncomplicated course, with radiographic union between the osteotomised scaphoid and the bone graft within three months. Six of seven patients had complete resolution of wrist pain; one (case 6) had minimal pain with strenuous work. The range of flexion- extension and the grip strength increased in all cases: average flexion-extension increased from $95^{\circ}$ to $137^{\circ}$; grip strength improved from $54 \%$ to $89 \%$ of that on the uninjured side. By contrast, the patient treated by radial styloidectomy had experienced no improvement, even after seven years.

The radiolunate angle was improved in all patients treated by corrective osteotomy, the difference from the contralateral wrist being reduced to less than $10^{\circ}$ in six of seven cases. The scapholunate angle showed less than $10^{\circ}$ difference from the normal side in five cases. The carpal height ratio was less than 0.01 different from the normal side in six cases, and scaphoid length was equal bilaterally in all seven cases.

\section{DISCUSSION}

Although malunion is unusual after a scaphoid fracture, a number of authors have discussed the possibility of malunion causing wrist pain (Fernandez 1984; Fisk 1984; Green 1985; Cooney et al 1988). Amadio et al (1989) reported that scaphoid malunion was associated with an increased risk of functional impairment.

There are three possible causes for scaphoid malunion. The first is when a displaced fracture unites after conservative treatment; this occurred in eight of our 10 patients. Cooney et al (1980) found that, of 13 displaced fractures, three resulted in malunion after plaster cast immobilisation. The second possibility is when a displaced fracture heals without treatment; this happened to two of our patients. The third possible cause is the surgical treatment of a displaced fracture without reduction. For example, the Matti-Russe technique (Russe 1960), widely used for the treatment of scaphoid 


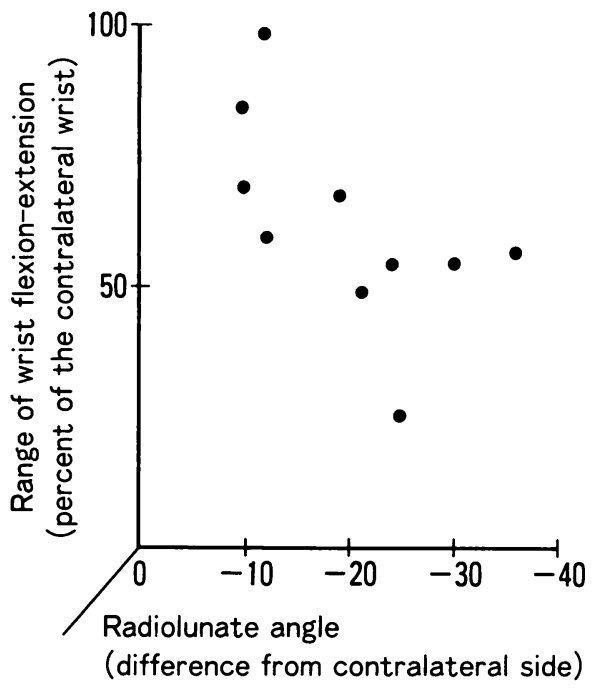

Fig. 3a

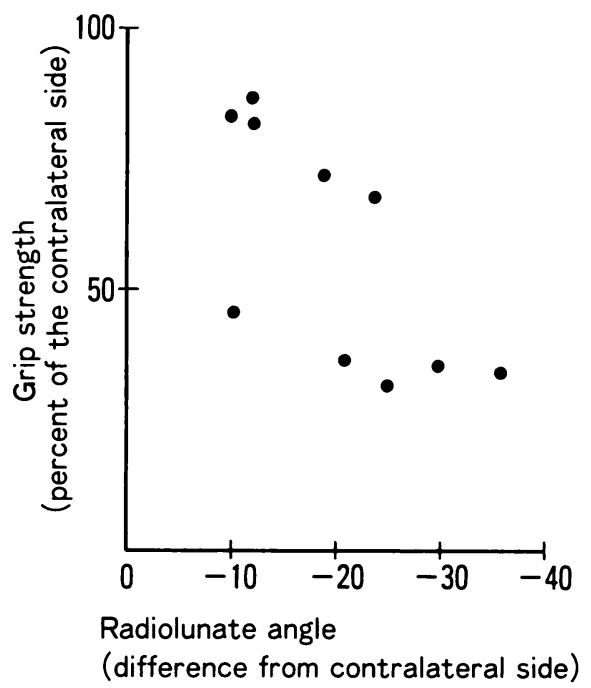

Fig. 3b

Figure 3a - The relationship between DISI deformity (radiolunate angle) and the range of flexion-extension of the wrist. There is a significant correlation (coefficient $=0.77, t$-test $\mathrm{p}<0.01$ ). Figure $3 \mathrm{~b}-$ Grip strength also shows a significant correlation with the severity of the DISI deformity (coefficient $=0.62, t$-test $\mathrm{p}<0.05$ )

nonunion, does not correct scaphoid and carpal deformities (Fernandez 1984).

Our patients with malunion had not only a limited range of movement, but also pain and decreased grip strength, similar to that seen in fracture or nonunion of the scaphoid. These symptoms have been thought to be due to a wide variety of causes: joint incongruity, posttraumatic synovitis, ligamentous injury and joint contracture have been cited. However, our study has shown that the severity of the DISI deformity correlated well with restriction of flexion-extension and with decreased grip strength and that corrective osteotomy produced remarkable improvements in wrist pain, range of flexionextension and grip strength. We therefore believe that carpal malalignment is primarily responsible for the symptoms associated with scaphoid malunion.

Corrective osteotomy by the technique we have described proved effective for symptomatic malunion in patients with no severe arthritic changes. The internal fixation with a Herbert screw is the most difficult aspect of the procedure, requiring repeated image intensifier control to obtain the correct position of the jig. We believe that a simpler method of rigid internal fixation is needed. If this was available then corrective osteotomy for the symptomatic malunion of scaphoid fractures would become a more common procedure.

No benefits in any form have been received or will be received from a commercial party related directly or indirectly to the subject of this article.

\section{REFERENCES}

Amadio PC, Berquist TH, Smith DK, Ilstrup DM, Cooney WP, Linscheid RL. Scaphoid malunion. J Hand Surg [Am] 1989; 14:679-87.

Burgess RC. The effect of a simulated scaphoid malunion on wrist motion. J Hand Surg [Am] 1987; 12:774-6.

Cooney WP, Dobyns JH, Linscheid RL. Fractures of the scaphoid: a rational approach to management. Clin Orthop 1980; 149:90-7.

Cooney WP, Linscheid RL, Dobyns JH, Wood MB. Scaphoid nonunion: role of anterior interpositional bone grafts. J Hand Surg [Am] $1988 ; 13: 635-50$

Eddeland A, Eiken O, Hellgren E, Ohlsson N-M. Fractures of the scaphoid. Scand J Plast Reconstr Surg 1975; 9:234-9.

Fernandez DL. A technique for anterior wedge-shaped grafts for scaphoid nonunions with carpal instability. $J$ Hand Surg [Am] 1984; 9:733-7.

Fisk GR. Carpal instability and the fractured scaphoid. Hunterian lecture 1968. Ann R Coll Surg Engl 1970; 46:63-76.

Fisk GR. Wedge grafting of the ununited fractured scaphoid: the Fisk operation. In: Rob CG, Smith ER, eds. Operative surgery: orthopaedics part II. London: Butterworths, 1979:540.

Fisk GR. The wrist: review article. J Bone Joint Surg [Br] 1984; 66B:396-407.
Green DP. The effect of avascular necrosis on Russe bone grafting for scaphoid nonunion. J Hand Surg [ Am] 1985; 10:597-605.

Herbert TJ, Fisher WE. Management of the fractured scaphoid using a new bone screw. J Bone Joint Surg [Br] 1984; 66-B:114-23.

Linscheid RL, Dobyns JH, Beabout JW, Bryan RS. Traumatic instability of the wrist: diagnosis, classification and pathomechanics. $J$ Bone Joint Surg [Am] 1972; 54-A :1612-32.

Nakamura R, Hori M, Horii E, Miura T. Reduction of the scaphoid fractures with DISI alignment. J Hand Surg [Am] 1987; 12: $1000-5$.

Russe O. Fracture of the carpal navicular: diagnosis, non-operative treatment, and operative treatment. J Bone Joint Surg [Am] 1960 42-A:759-68.

Sarrafian SK, Melamed JL, Goshgarian GM. Study of wrist motion in flexion and extension. Clin Orthop 1977; 126:153-9.

Weber ER. Biomechanical implications of scaphoid waist fractures. Clin Orthop 1980; 149:83-9.

Youm Y, McMurtry RY, Flatt AE, Gillespie TE. Kinematics of the wrist. I: An experimental study of radial-ulnar deviation and flexion-extension. J Bone Joint Surg [Am] 1978; 60-A: 423-31. 